\title{
3RD BIM/GIS INTEGRATION WORKSHOP AND 15TH 3DGEOINFO CONFERENCE 2020 - PREFACE
}

\author{
K. Wong ${ }^{1, *}$, C. Ellul ${ }^{2}$, J. Morley ${ }^{3}$, R. Home ${ }^{3}$ M. Kalantari ${ }^{4}$ \\ ${ }^{1}$ Risk Management Solutions, United Kingdom - Kelvin.Wong@ rms.com \\ ${ }^{2}$ University College London, United Kingdom - c.ellul@ucl.ac.uk \\ ${ }^{3}$ Ordnance Survey, United Kingdom - (j.morley,r.home)@os.uk \\ ${ }^{4}$ University of Melbourne, Australia - mohsen.kalantari@unimelb.edu.au
}

\section{PREFACE}

The interest in and use of 3D models in built environments is rapidly increasing, and they are now a key component of decisionmaking in areas including climate change mitigation (e.g., calculating solar panel potential, flood modelling, modelling housing age for retrofitting of thermal insulation), urban planning and cadastral systems (modelling rights, restrictions and responsibilities in complex buildings, streamlining the process to issue planning permits, design of existing or new developments) and infrastructure (construction, transport, utility management and modelling, asset management). 3D models are also an integrator for the data underpinning smart cities-knowing where a sensor is in 3D space allows the data to be integrated with the surrounding context-for example, noise data could be integrated with traffic information. Reflecting this interest, national mapping and cadastral agencies (NMCA) including Ordnance Survey (GB) are now increasingly generating 3D mapping at national scale, and there is extensive research as to how this data can be integrated with another emerging source of 3D models such as building information modelling (BIM).

These trends were evident during the 3rd BIM/GIS Integration Workshop and 15th 3DGeoInfo 2020 events, which were cohosted by University College London and Ordnance Survey (GB) in September 2020. The workshop and conference brought together international researchers from academia, industry, government and national mapping and cadastral agencies in the field of $3 \mathrm{D}$ geoinformation, in an interdisciplinary gathering of researchers in the fields of data collection, data management, data quality, data analysis, advanced modelling approaches, applications, users, visualisation, augmented reality, artificial intelligence and many more.

This year's theme was Users and Use Cases. The workshop and conference covered a wide range of topics including 3D data acquisition and processing, 3D city modelling and related standards, visualisation and dissemination of 3D data, augmented and virtual reality, 3D and Artificial Intelligence/Machine Learning. Three sessions of the BIM/GIS Integration Workshop were dedicated to Applications of BIM/GIS Integration, and an entire day of 3DGeoInfo 2020 to Users and Use Cases within 3DGeoInfo. Additionally, two sessions were specifically aimed at NMCA participants.

Although initially intended to be a face-to-face event in London, the team rapidly adjusted to the emerging COVID-19 situation, identifying an online solution that facilitated and encouraged participant interaction. This meant that the events could still provide a platform for learning, discussion, and exchange of ideas that they have been able to in previous years, as well as providing opportunities to promote international collaboration in these topics. This special issue of the ISPRS International Archives of Photogrammetry, Remote Sensing and Spatial Information Sciences contains 23 papers selected by a double-blind peer review involving a minimum of two reviewers, presenting research on topics including visualisation, point cloud management, virtual reality, data interoperability, data quality, generating national 3D datasets, indoor 3D, urban planning/permits and underground data management. The editors would particularly like to thank:

1. The speakers at the conferencein particular the three keynote speakers Dr Anne Kemp OBE (Atkins), Polly Hudson (University College London) and Professor Jantien Stoter (TU Delft) who went above and beyond expectations to prerecord talks while also being available live for questions.

2. The participants-who supported the online event, with participation rates being equal to those of previous face to face events

3. The members of the Scientific Committee - for their time and valuable comments, which contributed to the high quality of the papers. Reviews were contributed by: Alias AbdulRahman, Giorgio Agugiaro, Ken Arroyo Ohori, Apostolos Arvanitis, Behnam Atazadeh, Ana Basiri, Filip Biljecki, Lars Bodum, Pawel Boguslawski, Rémi Cura, Sagi Dalyot, Youness Dehbi, Abdoulaye Abou Diakité, Efi Dimopoulou, José-Paulo Duarte de Almeida, Lucía Díaz Vilariño, Claire Ellul, George Floros, Gerhard Groeger, Lars Harrie, Rollo Home, Umit Isikdag, Martin Kada, Mohsen Kalantari, Ismail Rakip Karas, Baris Kazar, Mila Koeva, Thomas Kolbe, Anna Labetski, Hugo Ledoux, Claudine Metral, Jeremy Morley, Ivin Amri Musliman, Francesca Noardo, Léon Olde Scholtenhuis, Claudio Persello, Jacynthe Pouliot, Siva Ravada, Kean Huat Soon, Rudi Stouffs, Edward Verbree, Stelios Vitalis, Kelvin Wong, Shen Ying.

We are also grateful to the work of the 'virtual' organising committee (George Floros, Ana Basiri) and the finance team at UCL (in particular Gary Green and Julija Melesko), without whom organising this conference would have been far more complicated.

And finally-the conference would not have been possible without the support of our sponsors - co-organisers Ordnance Survey (https://www.ordnancesurvey.co.uk/), EuroSDR (http://eurosdr.net/), 1Spatial (https://1spatial.com/), and the ISPRS International Journal of GeoInformation (https://www.mdpi.com/journal/ijgi).

\footnotetext{
* Corresponding author
} 